\title{
An Impact of Instructional Design for Unplugged Programming using Drones on Learner Motivation
}

\author{
Seungki Shin \\ Institute of Global Education for the Advancement of Innovative Learning, \\ Daegu National University of Education, Republic of Korea \\ Innocreate2010@gmail.com
}

\begin{abstract}
Computational thinking and coding education are important factors for developing the capacity of future society. In early childhood and elementary schools, Unplugged Programming activities are being implemented as a coding education method to enhance computational thinking skills. The purpose of this study was to design and apply an instructional process using drones and to examine the statistical significance of the effects of learners' motivation through pre- and post-tests. Learners' motivation was measured by examining changes in four elements of ARCS (Attention, Relevance, Confidence, Satisfaction), with statistically significant results in the Confidence and Satisfaction domains.
\end{abstract}

\section{Introduction}

Computational thinking and coding education are important factors of future social competence that have become part of the education system worldwide [1-3]. Computational thinking is a problem-solving process associated with the process of computing that involves understanding a problem through abstraction techniques, deriving the solution method, and automating the problem-solving process using algorithms [1-5].

Coding education has been limited to the interests that people have had in the past or their access to a selective viewpoint as a necessary part of a job, but recently it has been expanded to include the view that everyone should learn [4] [5]. This direction is regarded as an essential element of preparing future society with problem-solving abilities based on computational thinking, and it constitutes an important consideration in the teaching and learning design process for programming education because it forms the basis of coding education $[6,7]$.

This means that the ultimate goal of coding education is to expand computational thinking beyond the objective of developing programmers, by emphasizing the importance of learning and experiencing the problem-solving process [3-7].

In addition to the importance of computational thinking, the K-12 coding education system is organized around the world to structure the curriculum. However, in early childhood and elementary schools, although the teaching and learning environment for improving computational thinking through the use of computer technology is cognitive, development of such skills is difficult considering the developmental stage [8-10]. Therefore, there has been some research on activities that access computer science concepts to develop computational thinking without computing equipment, which are defined as "unplugged programming" [2,9]. Unplugged programming is a process whereby computer science concepts are processed without the use of computing

Received (May 18, 2018), Review Result (August 13, 2018), Accepted (August 20, 2018) 
equipment. Therefore, given that the effect of education can be reduced if the interest of the learner is not considered, certain elements can be omitted [2] [10].

In this study, 119 students from four elementary schools located in Gyeongbuk province, Korea, were selected to learn unplugged programming, which teaches the concept of algorithms through control activities using drones. The purpose of this study was to investigate the effects of learners' motivation on computer science.

\section{Unplugged Activities for Computer Science Education}

To prevent the adverse effects on teaching and learning of the difficulties associated with using computing devices in K-2 and K-3 computer science education, problemsolving learning through unplugged programming activities was attempted [8-10]. According to national level guidelines, in particular, which are referred to as excellent countries among the countries that organize coding education at the national level, Korea's software education operation guidelines, it is necessary to use unplugged activities in lower elementary school grades [1-3].

In the unplugged programming system, if the contents of learning are not taken into consideration in the teaching and learning design process, motivation may be inhibited or negative effects on creativity may develop $[2,10]$.

Therefore, in this study, we designed an instructional process that could enhance problem- solving abilities and creativity, and attempted to examine the effects of drones.

\section{Drones for Education}

Recently, in the field of STEM fusion education, various research is being carried out to create conditions for realizing learners' ideas by utilizing various physical computing technologies. Specifically, the introduction and verification of research methods on the need for teaching and learning using drones, as well as methods that can be used as tools in fusion education are being carried out continuously.

Krajnik et al., (2011) introduced the possibility of STEM education using drones and presented a variety of possibilities [11]. The results of this study are as follows.

Hanssen (2016) emphasized that drones are an important tool when it comes to preparing for the future and considering the impact on the industrial base. All students should participate in fusion education using drones and make an effort to strengthen competencies with respect to career education [12].

Nitschke et al., (2014) proposed a fusion education approach using quadcopter drones to develop real life-oriented problem-solving abilities through a problem-solving process based on "design thinking" [13].

Ahn Tae-won and others (2016) presented a teaching-learning module based on "creative design" (MCU Basic Training $\rightarrow$ Communication Control $\rightarrow$ Posture Sensor Processing $\rightarrow$ Motor Thrust Test $\rightarrow$ Hovering Experiment $\rightarrow$ Mobile Flight Experiment $\rightarrow$ Extension Module Practice $\rightarrow$ Creative Design Project). A convergence education plan was constructed and verified [14]. These projects show that convergence education using drones is ongoing and that it is an effective tool for enhancing competence to prepare students for the future based on the teaching-learning effect on problem-solving abilities.

\section{Course Design using Drones for Computational Thinking}

The coursework was constructed based on the Creative Computational Thinking (CCT) teaching and learning model presented by Shin (2017) to design a drone teaching and learning process that could enhance problem-solving abilities and creativity based on computational thinking. Figure 1 illustrates its composition [15]. 


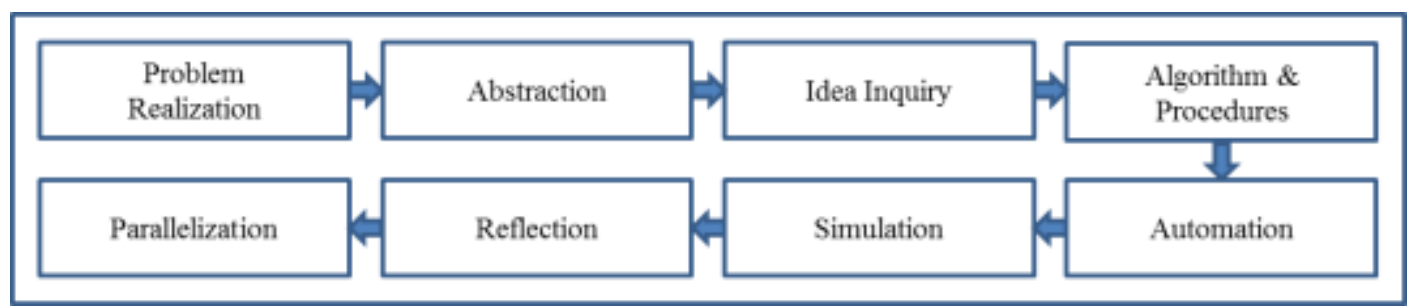

Figure 1. Instructional Model on Creative Computational Thinking (Shin, 2017, p. 58)

Based on the CCT teaching and learning model shown in Figure 1, the contents of the study are as shown in Table 1 below and involve the performance of coding learning based on computational thinking using drones. To solve a problem using drones, we developed an idea that would utilize the drone in the problem-solving process and selected it so that the optimal algorithm could be derived. Table 1 summarizes the results of the study. The subjects were 119 subjects for a period of one month and eight weeks for two weeks for four weeks.

Table 1. Lesson Goals of the CCT Instructional Model using Drones

\begin{tabular}{|l|l|l|}
\hline No & Stage & Lesson Goal \\
\hline 1 & Problem Realization & $\begin{array}{l}\text { Students should identify the problem presented and } \\
\text { identify the problem to be solved. }\end{array}$ \\
\hline 2 & Abstraction & $\begin{array}{l}\text { Students use drones to distinguish between the } \\
\text { necessary and unnecessary elements to solve the } \\
\text { problem. }\end{array}$ \\
\hline 3 & Idea Inquiry & $\begin{array}{l}\text { Students use the drones to create various ideas for } \\
\text { solving problems. }\end{array}$ \\
\hline 4 & $\begin{array}{l}\text { Algorithm and } \\
\text { Procedures }\end{array}$ & $\begin{array}{l}\text { Students use the drones to choose the best ideas to solve } \\
\text { their problems. }\end{array}$ \\
\hline 5 & Automation & $\begin{array}{l}\text { Students specify how they can control the drone to apply } \\
\text { the selected algorithm to the problem-solving process. }\end{array}$ \\
\hline 6 & Simulation & $\begin{array}{l}\text { Students use the drone to actually apply the algorithm } \\
\text { chosen for the problem-solving process. }\end{array}$ \\
\hline 7 & Reflection & $\begin{array}{l}\text { Students use the drone to modify and supplement the } \\
\text { algorithm applied in the problem-solving process to } \\
\text { derive the best algorithm. }\end{array}$ \\
\hline 8 & Parallelization & $\begin{array}{l}\text { Solve the problem by applying the optimal algorithm } \\
\text { derived by students to other similar problem situations. }\end{array}$ \\
\hline
\end{tabular}

\section{Assessment Tools for Motivation Using Course Interests}

The purpose of this study was to investigate the results of a pre-test and post-test on unplugged programming based on computational thinking using drones. As an evaluation tool, Keller (1993)'s Course Interest Survey was applied to the drone-based teaching and learning process. As shown in Table 2, four items (Attention, Relevance, Confidence, Satisfaction) were evaluated, and the detailed status of each item and Cronbach's alpha value were found. 
Table 2. Assessment Tools from the Course Interest Survey (Keller, 1993)

\begin{tabular}{|c|c|c|}
\hline Factors & Questions & Cronbach's alpha \\
\hline Attention & $1,(4), 10,15,21,24,(26), 29$ & .649 \\
\hline Relevance & $2,5,(8), 13,20,22,23,(25), 28$ & .700 \\
\hline Confidence & $3,(6), 9,(11),(17), 27,30,34$ & .704 \\
\hline Satisfaction & $(7), 12,14,16,18,19,(31), 32,33$ & .748 \\
\hline
\end{tabular}

\section{Results}

The 119 students who participated in the unplugged programming class using the drone were pre-tested, and a post-test was conducted after four weeks of the teaching and learning process. To prevent an increase in adaptation to the evaluation, the pre- and posttests were conducted in the same order but using different tests. The results of the pre- and post-tests were subjected to the corresponding sample t-test, and the statistical significance was verified using SPSS.

As shown in Table 3, the statistical significance was verified using a significant 116 out of 119 participants. The mean value was not statistically significant in Attention and Relevance. Confidence and Satisfaction items showed a statistically significant difference, and $\mathrm{p}<.01$ and $\mathrm{p}<.05$, respectively.

Table 3. Results of T-test for the Course Interest Survey

\begin{tabular}{|c|c|c|c|c|c|}
\hline Factors & $\begin{array}{c}\text { Pre-test } \\
M(S D)\end{array}$ & $\begin{array}{c}\text { Post-test } \\
M(S D)\end{array}$ & $d f$ & $t$ & $P$ \\
\hline Attention & $27.14(4.10)$ & $26.41(4.99)$ & 115 & 1.69 & .093 \\
\hline Relevance & $32.22(5.69)$ & $32.46(6.36)$ & 115 & -.43 & .667 \\
\hline Confidence & $28.00(5.62)$ & $29.31(4.06)$ & 115 & 2.69 & $.008^{* *}$ \\
\hline Satisfaction & $32.78(6.22)$ & $33.95(5.27)$ & 115 & 2.12 & $.035^{*}$ \\
\hline
\end{tabular}

Note. $\mathrm{N}$ for the experimental group $=116$ with missing 3 cases. $* p<.05, * * p<.01 . \mathrm{M}$ means mean score and SD means standard deviation.

The 119 students who participated in the experiment formed five classes in total. Two classes were randomly selected to verify the validity of the experimental instrument and the reliability of the designed teaching and learning process. The groups were named Group A and Group B, and constructed so that there was no significance that could be given separately. Group A performed the pre-test before pre-test separately from pre-test and post-test. Group B performed the post-test separately after post-test.

In Table 4, for Group A, Phase 1 refers to a separate pre-test performed one month before the pre-test, and Phase 2 refers to the actual pre-test before the test. In the case of Group B, Phase 1 means the post-test after the experiment was applied, and Phase 2 means a separate post-test conducted one month after the post-test. The results of the experiment showed that there was no statistical difference in Attention, Confidence, or Satisfaction in both Group A and Group B. However, it can be seen that the learners' responses in Group B were statistically significantly lower for the Relevance item. 


\section{Table 4. Results of T-test from the Course Interest Survey for Validity} Verification

\begin{tabular}{|c|c|c|c|c|c|c|}
\hline Factors & Group & $\begin{array}{c}\text { Phase1 } \\
M(S D)\end{array}$ & $\begin{array}{c}\text { Phase2 } \\
M(S D)\end{array}$ & $d f$ & $t$ & $p$ \\
\hline \multirow{2}{*}{ Attention } & Group A & $27.08(3.36)$ & $28.17(3.31)$ & 23 & -1.54 & .136 \\
\cline { 2 - 7 } & Group B & $26.86(4.09)$ & $27.52(4.10)$ & 22 & .91 & .372 \\
\hline \multirow{2}{*}{ Relevance } & Group A & $31.96(4.96)$ & $33.04(5.44)$ & 23 & -1.80 & .085 \\
\cline { 2 - 7 } & Group B & $34.39(5.67)$ & $32.74(5.47)$ & 22 & 2.17 & $.041 *$ \\
\hline \multirow{2}{*}{ Confidence } & Group A & $29.21(3.06)$ & $28.96(3.11)$ & 23 & .48 & .630 \\
\cline { 2 - 7 } & Group B & $28.48(5.45)$ & $30.04(4.84)$ & 22 & 1.71 & .101 \\
\hline \multirow{2}{*}{ Satisfaction } & Group A & $33.96(3.80)$ & $34.04(4.29)$ & 23 & -.18 & .858 \\
\cline { 2 - 7 } & Group B & $35.22(4.73)$ & $34.83(5.18)$ & 22 & .53 & .596 \\
\hline
\end{tabular}

Note. $\mathrm{N}$ for the experimental group $=24$. ${ }^{*} p<.05 . \mathrm{M}$ means mean score and SD means standard deviation.

\section{Findings and Discussion}

The purpose of this study was to investigate the influence of drones on students' motivation by designing an unplugged programming lesson using a drone for creativity and problem-solving based on computational thinking for the lower grades of elementary school. Using the Course Interest Survey of Keller (1993), we examined the effectiveness of the test.

The results of the experiment show that learner motivation was improved in the Confidence and Satisfaction areas among the four areas of ARCS (Attention, Relevance, Confidence, Satisfaction), as shown in Table 3 and Figure 2. On the other hand, there was no statistical significance in the Attention and Relevance domains.

The validity of the designed teaching and learning process was verified before the pretest and after the post-test to examine the validity of the drone-based unplugged programming designed for the experiment. However, due to the statistical significance in the result of the significant decrease in the Relevance area, it is necessary to investigate whether the result was caused by the experiment. In addition, we should discuss similar tendencies of Satisfaction and Relevance shown in Figure 2 and the causal relationship between the opposites of the Confidence and Attention domains.

\section{References}

[1] Ministry of Education, Korea, Elementary School Curriculum. \#2015-74 (Annex 2), (2015).

[2] Ministry of Education, Korea, Informatics Curriculum. \#2015-74 (Annex 10), (2015).

[3] Ministry of Education, Korea, Software Education Instructional Guidance, (2015).

[4] J. M. Wing, "Computational thinking", Communications of the ACM, vol. 49, no. 3, (2006), pp. 33-35.

[5] J. M. Wing, "Computational thinking and thinking about computing", Philosophical transactions of the royal society of London A: mathematical, physical and engineering sciences, vol. 366, no. 1881, (2008), pp. 3717-3725.

[6] S. Shin and Y. Bae, "A Study on the Hierarchical Instructional System Design of Software Education by School System", Journal of The Korean Association of Information Education, doi: http://dx.doi.org/10.14352/jkaie.2015.19.4.533, vol. 19, no. 4, (2015) December, pp. 533-544.

[7] Computer Science Teachers Association (CSTA) and the International Society for Technology in Education (ISTE), Computational Thinking Teacher Resources. Second Edition, (2011).

[8] C. P. Brackmann, M. Román-González, G. Robles, J. Moreno-León, A. Casali and D. Barone, "Development of Computational Thinking Skills through Unplugged Activities in Primary School", In Proceedings of the 12th Workshop on Primary and Secondary Computing Education, ACM, (2017) November, pp. 65-72.

[9] T. C. Bell, I. H. Witten and M. Fellows, "Computer Science Unplugged: Off-line activities and games for all ages”, Computer Science Unplugged, (1998). 
[10] S. Jiang and G. K. Wong, "Are Children More Motivated with Plugged or Unplugged Approach to Computational Thinking?", In Proceedings of the 49th ACM Technical Symposium on Computer Science Education, ACM, (2018) February, pp. 1094-1094.

[11] M. J. Mayo, "Video games: A route to large-scale STEM education?", Science, vol. 323, no. 5910, (2009), pp. 79-82.

[12] S. Hanssen, "Drone Class: Keeping Coursework Current as Technology Advances", Community College Journal of Research and Practice, vol. 40, no. 10, (2016), pp. 871-874.

[13] C. Nitschke, Y. Minami, M. Hiromoto, H. Ohshima and T. Sato, "A quadrocopter automatic control contest as an example of interdisciplinary design education", In Control, Automation and Systems (ICCAS), 2014 14th International Conference on IEEE, (2014) October, pp. 678-685.

[14] T. Ahn, W. Lee and H. Park, "A Study on Drone Education Module for Creative Design", Summer Conference at The Institute of Electronics and Information Engineers, (2016), pp. 2107-2108.

[15] S. Shin, "A Study on the Development of Creative Computational Thinking Instructional Model and Verification of its Effectiveness", Dissertation for Doctor of Philosophy in the University of Georgia, (2017).

[16] T. Krajník, V. Vonásek, D. Fišer and J. Faigl, "AR-drone as a platform for robotic research and education", In International Conference on Research and Education in Robotics, Springer Berlin Heidelberg, (2011) June, pp. 172-186

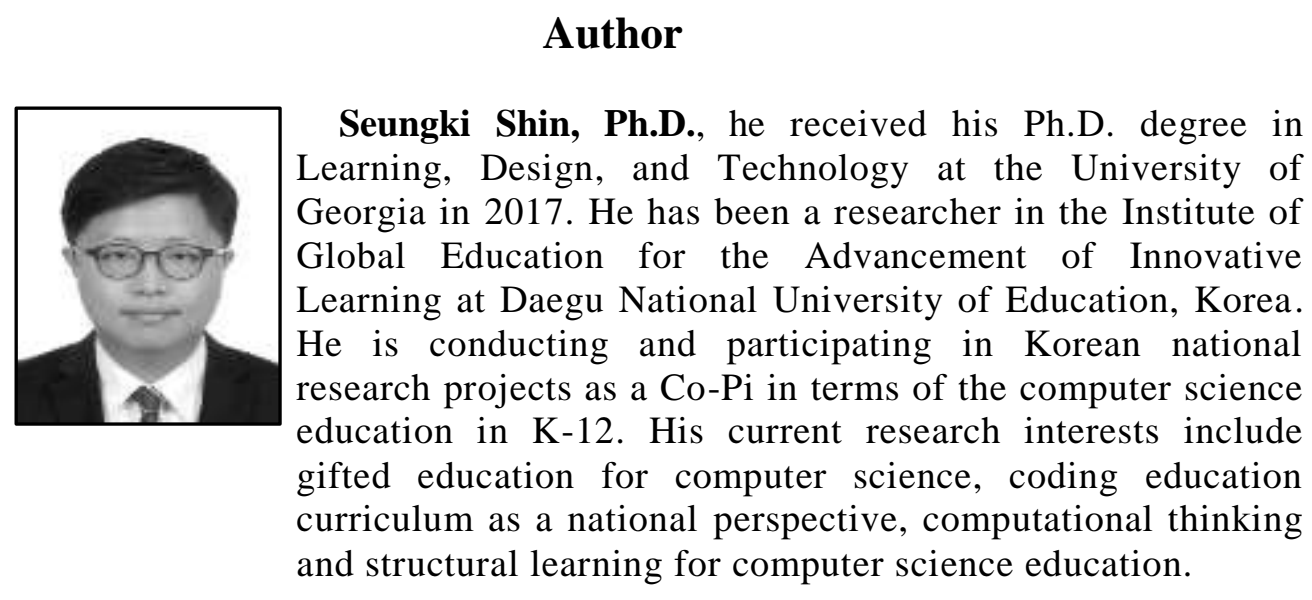

